\title{
HUBUNGAN SENAM KEGEL PADA IBU HAMIL PRIMIGRAVIDA DENGAN KEJADIAN RUPTUR PERINEUM DI KLINIK PRATAMA JANNAH MEDAN TEMBUNG DAN KLINIK PRATAMA TANJUNG DELI TUA TAHUN 2018
}

\author{
Yusrawati hasibuan, Hafizah Nurwindayu \\ Jurusan Kebidanan Politehnik Kesehatan Kemenkes Medan
}

\begin{abstract}
Abstrak
Berdasarkan Survei Demograsi dan Kesehatan Indonesia, penyebab kematian ibu tertinggi pada tahun 2013 adalah perdarahan. Salah satu penyebabperdarahan adalah robekan perineum. Tujuan penelitian ini adalah untuk mengetahui hubungan Senam Kegel dengan kejadian ruptur perineum di Klinik Pratama Jannah Medan Tembung dan Klinik Pratama Tanjung Deli Tua. Penelitian ini bersifat analitik korelasi dengan pendekatan Cross Sectional. Sampel sebanyak 30 responden, Kelompok pertama kelompok yang melakukan Senam Kegel sedangkan kelompok kedua kelompok kontrol.. Data dianalisis dengan ChiSquare.Hasil menunjukkan bahwa Ibu hamil primigravida trimester III yang melakukan Senam Kegel mengalami ruptur perineum 4 orang (27\%), sedangkan yang tidak melakukan mengalami ruptur perineum 13 orang $(87 \%)$. Hasil uji nilai $p$ value $(0,003)<\alpha(0,05)$ menunjukkan adanya hubungan bermakna antara Senam Kegel dengan terjadinya ruptur perineum.Saran kepada tenaga kesehatan khususnya bidan yang bekerja di tempat penelitian memberikan penyuluhan dan motivasi para ibu hamil agar melakukan Senam Kegel secara rutin selama kehamilan agar dapat mencegah perdarahan akibat ruptur perineum.
\end{abstract}

Kata kunci : Primigravida, Ruptur Perineum, Senam Kegel

\section{PENDAHULUAN}

Ruptur Perineum merupakan sobekan yang terjadi saat bayi lahir baik secara spontan maupun dengan alat atau tindakan. Kebanyakan wanita yang mengalami ruptur perineum adalah wanita yang melahirkan anak pertama. Hal tersebut dapat terjadi karena otot-otot dasar panggul belum pernah teregang sebelumnya. Otot-otot dasar panggul harus memiliki elastisitas yang baik untuk mempersiapkan dan menghadapi persalinan dengan harapan sewaktu terjadi relaksasi otot-otot tersebut akan teregang dengan optimal yang secara alamiah dapat melewatkan bayi secara nyaman dan berkontraksi kembali untuk menyokong organ panggul setelah bayi dilahirkan (Oxorn, 2010).

Berdasarkan Survei Demograsi dan Kesehatan Indonesia, penyebab kematian ibu pada tahun 2013 adalah perdarahan (30,3\%), Hipertensi (27,1\%), infeksi (7,3\%), partus lama (1,8\%) dan abortus (1,6\%). Sementara itu penyebab lain-lain juga berperan cukup besar dalam menyebabkan kematian ibu (40,8\%). Yang dimaksud dengan penyebab lain-lain adalah penyebab kematian ibu secara tidak langsung, seperti kondisi penyakit kanker, ginjal, jantung, tuberkulosis, atau penyakit lain yang diderita ibu (Kemenkes, 2014).

AKI di Indonesia karena perdarahan post partum mempunyai peringkat yang tinggi, salah satu penyebab perdarahannya adalah Atonia Uteri atau tidak adanya kontraksi pada uterus, dan robekan perineum menjadi penyebab perdarahan postpartum kedua (Kristianti, 2015).

Faktor yang menyebabkan terjadi ruptur perineum antara lain faktor ibu yaitu pada saat kehamilan dan persalinan. Pada saat kehamilan dipengaruhi oleh pengetahuan, pendidikan, perawatan prenatal care dan kondisi fisik ibu. Sedangkan saat persalinan dipengaruhi oleh paritas, cara meneran, dan kondisi perineum. Faktor penyebab robekan perineum yang kedua yaitu janin diantaranya dikarenakan faktor berat bayi baru lahir dan presentasi bayi (Turlina, 2015).

Bahaya dan komplikasi akibat terjadinya robekan jalan lahir antara lain perdarahan dan infeksi serta gangguan ketidaknyamanan. Perdarahan pada robekan jalan lahir dapat menjadi hebat khususnya pada robekan jalan lahir derajat dua atau tiga atau jika robekan meluas kesamping atau naik ke vulva mengenai klitoris. Luka perineum dapat dengan mudah terinfeksi karena letaknya dekat dengan anus memungkinkan sering terkontaminasi feses. Infeksi juga dapat menjadi sebab luka tidak segera menyatu sehingga timbul jaringan parut, sehingga menimbulkan ketidaknyamanan (Turlina, 2015).

Salah satu cara yang dapat dilakukan untuk mengurangi robekan perineum adalah dengan melakukan senam Kegel. Senam Kegel merupakan senam untuk menguatkan otot dasar panggul menjelang persalinan, tujuannya untuk melenturkan jaringan perineum sebagai jalan lahir bayi, menguatkan otot-otot dasar panggul dan 
membantu mencegah masalah inkontinensia urine (Kristianti, 2015).

Prosedur senam Kegel dapat diingat dan dilakukan bersama aktifitas yang berkaitan dengan kegiatan ibu sehari hari. Seperti saat ibu duduk di kamar mandi setelah berkemih dan ini adalah posisi relaks untuk mengkontraksi otot tersebut, serta pada saat ibu ingin tidur dan dalam keadaan apapun. Melakukan senam Kegel secara teratur dapat membantu melenturkan jaringan perineum ibu menyambut persalinan.

Penelitian Turlina (2015) Hubungan Senam Hamil dengan Terjadinya Robekan Perineum Spontan di BPM Wiwik Azizah Said Desa Duriwetan Kecamatan Maduran Kabupaten Lamongan menunjukkan bahwa ibu bersalin spontan yang mengikuti senam hamil hampir seluruhnya $(84,6 \%)$ tidak mengalami robekan perineum dan sebagian kecil (15,4\%) yang mengalami robekan perineum. Sedangkan ibu bersalin spontan yang tidak mengikuti senam hamil sebagian besar (62,5\%) mengalami robekan perineum dan hampir sebagian (37,5\%) tidak mengalami robekan perineum. Jadi prevalensi robekan perineum lebih tinggi (62,5\%) pada ibu bersalin spontan yang tidak melakukan senam hamil dari pada yang melakukan senam hamil (15,4\%).

Berdasarkan masalah diatas, peneliti tertarik untuk melakukan penelitian dengan judul "Hubungan Senam Kegel Pada Ibu Hamil Primigravida Dengan Kejadian Ruptur Perineum Pada Ibu Bersalin di Klinik Pratama Jannah Medan Tembung dan Klinik Pratama Tanjung Kec. Deli Tua Tahun 2018”

\section{Tujuan}

Menganalisis kejadian ruptur perineum pada ibu hamil primigravida yang melakukan Senam Kegel dan tidak melakukan Senam Kegel.

\section{METODE PENELITIAN}

Penelitian ini menggunakan desain penelitian analitik korelasional dengan menggunakan pendekatan cross sectional. Populasi adalah ibu hamil primigravida di Klinik Bersalin Pratama Jannah Medan Tembung dan Klinik Pratama Tanjung Deli Tua. Sampel sebanyak 30 responden. Kelompok pertama merupakan kelompok yang melakukan Senam Kegel sedangkan kelompok kedua merupakan kelompok kontrol. Analisamenggunakan uji Chi-Square.

\section{HASIL PENELITIAN}

Tabel Distribusi Frekuensi Kejadian Ruptur Perineum pada Persalinan Normal di Klinik Pratama Jannah Medan Tembung dan Klinik Pratama Tanjung Deli Tua Tahun 2018

\begin{tabular}{ccc}
\hline $\begin{array}{c}\text { Ruptur } \\
\text { Perineum }\end{array}$ & Frekuensi & (\%) \\
\hline Ruptur & 17 & 56 \\
Tidak Ruptur & 13 & 44 \\
\hline Jumlah & 30 & 100
\end{tabular}

Berdasarkan tabel 4.5 di atas didapatkan bahwa dari keseluruhan primipara yang mengalami ruptur perineum pada persalinan sebanyak $56 \%$ dan yang tidak mengalami ruptur perineum sebanyak 44\%.

Tabel 2 Distribusi Hasil Uji Tabulasi Silang (ChiSquare) Antara Senam Kegel dengan Kejadian Ruptur Perineum

\begin{tabular}{|c|c|c|c|c|c|}
\hline & & & \multicolumn{2}{|c|}{$\begin{array}{l}\text { Ruptur } \\
\text { Perineum }\end{array}$} & \multirow[t]{2}{*}{ Total } \\
\hline & & & Ya & Tidak & \\
\hline \multirow{4}{*}{$\begin{array}{l}\text { Senam } \\
\text { Kegel }\end{array}$} & Yo & $\mathrm{n}$ & 4 & 11 & 15 \\
\hline & $\mathrm{Ya}$ & $\%$ & $13 \%$ & $37 \%$ & $50 \%$ \\
\hline & Tid & $\mathrm{n}$ & 13 & 2 & 15 \\
\hline & $\mathrm{ak}$ & $\%$ & $43 \%$ & $7 \%$ & $50 \%$ \\
\hline \multirow{2}{*}{ Tota } & & $\mathrm{n}$ & 17 & 13 & 30 \\
\hline & & $\%$ & $56 \%$ & $44 \%$ & $100 \%$ \\
\hline
\end{tabular}

Dari tabel di atas dapat dilihat bahwa dari 15 responden yang melakukan senam kegel terdapat 11 responden (37\%) yang tidak ruptur dan 4 responden (13\%) terjadi ruptur. Sedangkan dari 15 responden yang tidak melakukan senam kegel terdapat 13 responden (43\%) terjadi ruptur dan 2 responden (7\%) tidak ruptur.

Hasil uji Chi-Square menghasilkan nilai p-value 0,001 ( $p$ value $<0,05$ ) yang berarti Ho ditolak. Hal ini menunjukkan adanya hubungan yang bermakna antara Senam kegel dengan ruptur perineum di Klinik Pratama Jannah Medan Tembung dan Klinik Pratama Tanjung Deli Tua Tahun 2018.

\section{PEMBAHASAN}

Hasil penelitian menunjukkan bahwa Ibu hamil primigravida trimester III yang melakukan Senam Kegel serta mengalami ruptur perineum sebanyak 4 orang (27\%), sedangkan ibu hamil primigravida yang tidak melakukan senam kegel serta mengalami ruptur perineum sebanyak 13 orang (87\%).

Senam kegel adalah senam untuk menguatkan otot dasar panggul menjelang persalinan, membantu mencegah masalah inkonsistensia urine, serta dapat melenturkan jaringan perineum sebagai jalan lahir bayi (Kristianti, 2015). Senam Kegel apabila dilakukan saat kehamilan dapat membuat otot-otot dasar panggul menjadi supel, elastis, serta dapat meningkatkan sirkulasi darah pada daerah sekitar vagina, sehingga dapat membantu selama kehamilan dan proses persalinan (Khasanah, 2014).

Menurut Prawirohardjo (2009), ruptur atau robekan jalan lahir dapat terjadi akibat episitomi, robekan perineum spontan, trauma forceps atau ekstraksi vacum. Terdapat banyak faktor terjadinya ruptur meliputi paritas, jarak kehamilan, berat badan bayi serta riwayat persalinan.

Ruptur perineum dapat memberikan efek yang besar, mempengaruhi fisik, emosi dan hubungan seksual wanita selama hidupnya. Selain itu ruptur juga dapat menyebabkan terjadinya perdarahan post partum yang dapat mengakibatkan kematian. Oleh sebab itu, 
ruptur perineum yang merupakan trauma fisik perlu dicegah sehingga proses persalinan ibu terjadi secara menyenangkan dan memberikan pengalaman yang menyenangkan pula. Persalinan tanpa adanya trauma fisik khususnya ruptur perineum akan membuat ibu merasa lebih nyaman menghadapi persalinan selanjutnya dibandingkan dengan ibu yang sebelumnya pernah mengalami ruptur perineum.

Berdasarkan hasil uji nilai $p=0,003$. Nilai $\mathrm{p}<0,05$ menunjukkan adanya hubungan yang bermakna antara Senam Kegel dengan kejadian ruptur perineum di Klinik Pratama Jannah Medan Tembung dan Klinik Pratama Tanjung Deli Tua tahun 2018. Pengaruh dari gerakan senam melatih otot dasar panggul menjadi lebih elastis sehingga membantu proses persalinan dan mengurangi kejadian ruptur perineum.

Penelitian ini sejalan dengan penelitian sebelumnya yang dilakukan oleh Turlina tahun 2015 berjudul "Hubungan Senam Hamil dengan terjadinya Robekan Perineum Spontan Di BPM Wiwik Azizah Said Desa Duriwetan Kecamatan Maduran Kabupaten Lamongan”. Penelitian ini menggunakan desain penelitian analitik korelasi dengan jenis rancangan case control dan diperoleh nilai $\mathrm{p}=0,026$, nilai $\mathrm{p}<0,05$ sehingga dapat disimpulkan adanya hubungan antara senam hamil dengan terjadinya robekan perineum spontan. Menurut Anggraeni (2010) dalam Turlina (2015), senam kebugaran panggul bermanfaat untuk menguatkan otot-otot vagina dan sekitarnya (perineal) sebagai persiapan untuk persalinan, mempersiapkan diri baik fisik maupun mental. Otot panggul yang sering dilatih akan menguatkan otot-otot dasar panggul, meningkatkan aliran darah yang menuju ke vagina dan dubur sehingga dapat membantu ketika proses persalinan yaitu memudahkan kelahiran bayi tanpa banyak merobek jalan lahir serta mengembalikan elastisitas otot perineal (Kirana, 2013 dalam Turlina, 2015). Dari penelitian ini menunjukkan bahwa senam hamil dapat mengurangi resiko terjadinya robekan perineum meskipun masih ada hal-hal lain yang dapat mempengaruhi seperti faktor ibu, janin dan penolong.

Menurut asumsi peneliti Senam Kegel memiliki pengaruh terhadap terjadinya ruptur perineum. Ibu hamil primigravida memiliki resiko lebih besar mengalami ruptur perineum karena belum pernah terjadi peregangan pada otot-otot dasar panggul yang di sebabkan oleh kepala janin pada saat persalinan. Salah satu cara untuk melatih kekuatan otot-otot dasar panggul adalah dengan melakukan Senam Kegel. Ibu hamil primigravida yang melakukan Senam Kegel dapat mengurangi terjadinya ruptur perineum sehingga proses persalinan terjadi secara menyenangkan dan memberikan pengalaman persalinan yang menyenangkan pula.

\section{KESIMPULAN}

Hasil penelitian menunjukkan bahwa dari 30 sampel yang diteliti terdapat 17 sampel (56\%) mengalami ruptur perineum. Ibu hamil primigravida yang melakukan senam kegel serta mengalami ruptur perineum sebanyak $27 \%$ sedangkan ibu hamil primigravida yang tidak melakukan senam kegel serta mengalami ruptur perineum sebanyak 87\%. Berdasarkan penelitian yang dilakukan tentang Hubungan Senam Kegel Pada Ibu Hamil Primigravida dengan Kejadian Ruptur Perineum di Klinik Pratama Jannah Dan Klinik Pratama Tanjung menunjukkan nilai $\mathrm{p}$-value $=0,003<0,05$, yang berarti terdapat hubungan yang bermakna antara Senam Kegel dengan kejadian ruptur perineum Di Klinik Pratama Jannah Medan Tembung dan Klinik Pratama Tanjung Deli Tua

\section{DAFTAR PUSTAKA}

A’yunin. Qurratu. 2016. Hubungan faktor Resiko Anemia Dengan Kejaidan Abortus Spontan Di RSUP DR. M. Djamil Padang Tahun 2015. Skripsi. Universitas Andalas. Padang

BKKBN. 2008. Kesehatan Reproduksi. Jakarta: BKKBN

Corwin, Elizabeth j. 2009. Buku Saku Patofisiologi. Jakarta: EGC

Depkes RI. 2008. Asuhan Persalinan Normal. Edisi Revisi, Jakarta.

Dinkes. 2014. Profil Kesehatan 2012 Provinsi Sumatera Utara.

http://www.depkes.go.id/resources/download/pro fil/PROFIL_KES_PROVINSI_2012/02_Profil_ Kes_Prov.SumateraUtara_2012.pdf. November 2017.

Hidayat, A. Azis, 2012. Metode Penelitian Kebidanan dan Teknik Analisis Data. Jakarta: Salemba Medika

Kemenkes RI. 2014. Pusat Data dan Informasi Kesehatan Ibu.

http://www.depkes.go.id/resources/download/pus datin/infodatin/infodatin-ibu.pdf. 18 November 2017

Khasanah, Umi. 2014. Pengaruh Senam Kegel Pada Ibu Hamil Primigravida Terhadap Kejadian Ruptur Perineum Di Poned Surakarta. Skripsi. Universitas Sebelas Maret. Surakarta

Kristianti, Shinta. 2015. Hubungan Senam Kegel Pada Ibu Hamil primigravida TM III terhadap Derajat Robekan Perineum DI Wilayah Puskesmas Pembantu Bandar Kidul Kota Kediri. Jurnal Ilmu Kesehatan 3(2): 91-98.

Kuswandi, Lanny. 2014. Hypno-Birthing A gentle Way to Give Birth. Jakarta: Pustaka Bunda

Marmi, S.ST. 2016. Intranatal Care: Asuhan Kebidanan pada Persalinan. Yogyakarta: Pustaka Pelajar

Manuaba. 2010. Ilmu Kebidanan Penyakit Kandungan dan KB. Jakarta: EGC

Notoatmodjo, S. 2007. Promosi Kesehatan dan Ilmu Perilaku. Jakarta: Rineka Cipta

Oxorn, Harry. 2010. Ilmu Kebidanan Patologi dan Fisiologi Persalinan. Yogyakarta: Yayasan Essentia Medica

Prawirohardjo, Sarwono. 2009. Pelayanan Kesehatan Maternal dan Neonatal. Jakarta: JNPKKR, POGI 
Rahmi, Laili. 2010. Hubungan Usia, Tingkat Pendidikan, Dukungan Suami Dan Dukungan Keluarga Dengan Tingkat Kecemasan Menjeang Persalinan Pada Ibu Primigravida Trimester III Di Poliklinik KebidananRSUP DR. M. Djamil Padang Tahun 2009. Penelitian Keperawatan Maternitas

Riswati, A. Wisnu. 2015. Hubungan Senam Hamil Terhadap Terjadinya Robekan Perineum Pada Ibu Bersalin Primigravida Di Wilayah Kerja Puskesmas Tegalrejo Kecamatan Argomulyo Kota Salatiga.

Rukiyah, Ai Yeyeh. 2012. Asuhan Kebidanan IV. Jakarta: TIM

Sari, Eka Puspita. 2014. Asuhan Kebidanan Persalinan. Jakarta: TIM

Turlina, Lilin. 2015. Hubungan Senam Hamil Dengan Terjadinya Robekan Perineum Spontan Di BPM Wiwik Azizah Said Desa Duriwetan Kecamatan Maduran Kabupaten Lamongan. Jurnal Ilmu Kesehatan 07 (3): 16-21
Widianti, Anggriyana Tri \& Atikah. 2015. Senam Kesehatan. Yogyakarta: Nuha Medika

Wiknjosastro, H. 2011. Ilmu Kebidanan. Jakarta: Yayasan Bina Pustaka Sarwono

WHO. 2014. Maternal Mortality. World Health Organization 